\title{
Population-based cohort study of variation in the use of emergency cholecystectomy for benign gallbladder diseases
}

\author{
CholeS Study Group, West Midlands Research Collaborative*
}

Correspondence to: Dr R. S. Vohra, Trent Oesophago-Gastric Unit, City Campus, Nottingham University Hospitals NHS Trust, Hucknall Road, Nottingham NG5 1 PB, UK (e-mail: ravinder.vohra@nuh.nhs.uk)

\begin{abstract}
Background: The aims of this prospective population-based cohort study were to identify the patient and hospital characteristics associated with emergency cholecystectomy, and the influences of these in determining variations between hospitals.

Methods: Data were collected for consecutive patients undergoing cholecystectomy in acute UK and Irish hospitals between 1 March and 1 May 2014. Potential explanatory variables influencing the performance of emergency cholecystectomy were analysed by means of multilevel, multivariable logistic regression modelling using a two-level hierarchical structure with patients (level 1) nested within hospitals (level 2).

Results: Data were collected on 4744 cholecystectomies from 165 hospitals. Increasing age, lower ASA fitness grade, biliary colic, the need for further imaging (magnetic retrograde cholangiopancreatography), endoscopic interventions (endoscopic retrograde cholangiopancreatography) and admission to a non-biliary centre significantly reduced the likelihood of an emergency cholecystectomy being performed. The multilevel model was used to calculate the probability of receiving an emergency cholecystectomy for a woman aged 40 years or over with an ASA grade of I or II and a BMI of at least $25.0 \mathrm{~kg} / \mathrm{m}^{2}$, who presented with acute cholecystitis with an ultrasound scan showing a thick-walled gallbladder and a normal common bile duct. The mean predicted probability of receiving an emergency cholecystectomy was 0.52 (95 per cent c.i. 0.45 to 0.57 ). The predicted probabilities ranged from 0.02 to 0.95 across the 165 hospitals, demonstrating significant variation between hospitals.

Conclusion: Patients with similar characteristics presenting to different hospitals with acute gallbladder pathology do not receive comparable care.
\end{abstract}

*Members of the CholeS Study Group and West Midlands Research Collaborative are co-authors of this study and may be found under the heading Collaborators

Presented in part to the International Surgical Congress of the Association of Surgeons of Great Britain and Ireland, Belfast, UK, May 2016

Paper accepted 6 July 2016

Published online 23 September 2016 in Wiley Online Library (www.bjs.co.uk). DOI: 10.1002/bjs.10288

\section{Introduction}

Benign gallbladder diseases are a major global health burden ${ }^{1,2}$. RCTs, meta-analyses and expert consensus support the use of emergency cholecystectomy for most patients presenting with biliary colic, acute cholecystitis or gallstone pancreatitis ${ }^{3-9}$. Compared with delayed cholecystectomy following discharge after an acute admission, emergency cholecystectomy is associated with less gallbladder-specific morbidity, a shorter total length of hospital stay and similar operative morbidity ${ }^{10-15}$. Despite this evidence, there is still thought to be wide variation in the management of patients presenting with acute gallbladder pathology.
Reports from Europe, Asia and North America show rates of emergency cholecystectomy ranging from 12 to 88 per cent ${ }^{16-20}$. Within healthcare systems, patients with similar demographics and gallbladder pathologies also do not receive comparable care ${ }^{21}$. These variations may lead to avoidable morbidity, mortality and wasted resources ${ }^{22-24}$. Patient and hospital factors are often cited to justify these wide differences in the use of emergency cholecystectomy. Understanding the specific patient and hospital characteristics that lead to these variations might address inconsistencies in care and improve outcomes.

Over the past 8 years, trainee-led networks in the UK have adopted a collaborative approach to deliver 
population-level data collections using prospectively developed databases ${ }^{25}$. Using these networks, the aims of the present study were to identify patient and hospital characteristics associated with the use of cholecystectomy following acute admission with benign biliary disease, and to see how these factors influenced variations between hospitals in the use of emergency cholecystectomy.

\section{Methods}

This prospective cohort population-based study was carried out as described previously ${ }^{26}$. The protocol did not require research registration as anonymized, observational data were collected. This was confirmed by the online National Research Ethics Service decision tool (http://www.hra-decisiontools.org.uk/research/), and further supported by written confirmation and advice from the Research and Development Director at University Hospitals Birmingham NHS Foundation Trust, UK. The study was registered as a clinical audit or service evaluation at each participating hospital under the supervision of a named senior investigator (consultant surgeon).

\section{Inclusion and exclusion criteria}

Consecutive patients undergoing cholecystectomy for benign gallbladder diseases, including those undergoing emergency surgery, in acute UK and Irish hospitals between 1 March and 1 May 2014 were included, and data recorded using a prospectively developed database. This study analysed patients who had emergency admissions with right upper quadrant pain and symptoms; therefore, all patients with 'cholecystitis' had acute cholecystitis.

Patients were grouped according to the timing of cholecystectomy. Emergency cholecystectomy was defined as a cholecystectomy during an acute admission, and delayed cholecystectomy was defined as a planned cholecystectomy following an emergency admission with gallbladder disease. Open, laparoscopic, and laparoscopic converted to open operations were included. Patients who had a cholecystectomy for known gallbladder cancer or as a part of another surgical procedure, such as pancreaticoduodenectomy, bariatric, antireflux or transplant operations, were excluded.

\section{Outcome measure}

The primary outcome of interest was the performance of emergency cholecystectomy in comparison with delayed surgery.

\section{Data quality}

A quality assurance programme was developed ${ }^{26}$. This included a detailed study protocol, a pilot phase, and a requirement for a minimum of 95 per cent data completeness at submission. Case ascertainment and data accuracy were further validated by independent investigators at selected hospitals, who checked data accuracy in approximately 20 per cent of patients. These independent investigators were not involved in the original data collection.

\section{Explanatory variables}

Patient, disease and hospital characteristics were considered as potential explanatory variables influencing the performance of emergency cholecystectomy. A full list including definitions has been published previously ${ }^{26}$. Briefly, patient characteristics included here were: age, sex, ASA fitness grade $(\mathrm{I}-\mathrm{V})$ and BMI (less than $17.9 \mathrm{~kg} / \mathrm{m}^{2}$, underweight; $18.0-24.9 \mathrm{~kg} / \mathrm{m}^{2}$, normal; $25 \cdot 0-29.9 \mathrm{~kg} / \mathrm{m}^{2}$, overweight; $30.0-34.9 \mathrm{~kg} / \mathrm{m}^{2}$, $\bmod -$ erate obesity; $35.0 \mathrm{~kg} / \mathrm{m}^{2}$ and above, severe or very severe obesity). The following disease characteristics were considered: indication (biliary colic, acute cholecystitis, pancreatitis, common bile duct (CBD) stones), ultrasound findings, including gallbladder wall thickness (considered thick-walled if the wall was $2 \mathrm{~mm}$ or thicker) and a dilated $\mathrm{CBD}$ (CBD diameter $6 \mathrm{~mm}$ or greater), and other radiological investigations (CT, magnetic retrograde cholangiopancreatography (MRCP), endoscopic retrograde cholangiopancreatography (ERCP)).

Hospital characteristics were determined by a participating centre questionnaire and included hospital type (non-university, university-affiliated), specialist hepatobiliary centre (no, yes), acute hospital (no, yes), number of consultants within the reporting hospital performing cholecystectomy, country, number of beds within the reporting hospital (less than 100, 101-500, 501-1000, more than 1000) and the presence of an ERCP service. $\mathrm{HPB}$ centres were defined as hospitals offering tertiary $\mathrm{HPB}$ cancer resectional surgery as listed on the www.augis.org website. The hospital's policy regarding the ease of performing intraoperative cholangiography, and availability and use of dedicated emergency gallbladder operating lists, were considered. Grade of senior surgeon performing cholecystectomy, consultant presence at surgery and the consultant specialty were also recorded. Hospital volume of cholecystectomies was determined by ranking hospitals in order of increasing volume and selecting cut-off points that sorted patients into three evenly sized cohorts with low, medium and high volume. 
Table 1 Patient factors in relation to performance of emergency and delayed cholecystectomy

\begin{tabular}{|c|c|c|}
\hline & $\begin{array}{c}\text { Emergency } \\
\text { cholecystectomy } \\
(n=1451)\end{array}$ & $\begin{array}{c}\text { Delayed } \\
\text { cholecystectomy } \\
(n=3293)\end{array}$ \\
\hline \multicolumn{3}{|l|}{ Age (years) } \\
\hline$<40$ & $441(30.4)$ & $859(26 \cdot 1)$ \\
\hline $40-60$ & $510(35 \cdot 1)$ & $1161(35 \cdot 3)$ \\
\hline $61-80$ & $435(30 \cdot 0)$ & $1108(33.6)$ \\
\hline$>80$ & $65(4.5)$ & $165(5 \cdot 0)$ \\
\hline \multicolumn{3}{|l|}{ Sex } \\
\hline $\mathrm{F}$ & $1000(68.9)$ & $2189(66.5)$ \\
\hline M & $451(31 \cdot 1)$ & $1104(33.5)$ \\
\hline \multicolumn{3}{|l|}{$\mathrm{BMI}\left(\mathrm{kg} / \mathrm{m}^{2}\right)$} \\
\hline$<17.9$ & $6(0.4)$ & $17(0.5)$ \\
\hline $18 \cdot 0-24 \cdot 9$ & $262(18.1)$ & $667(20 \cdot 3)$ \\
\hline $25 \cdot 0-29 \cdot 9$ & $494(34.0)$ & $1108(33.6)$ \\
\hline $30 \cdot 0-34.9$ & $337(23 \cdot 2)$ & $805(24.4)$ \\
\hline$\geq 35.0$ & $250(17 \cdot 2)$ & $560(17 \cdot 0)$ \\
\hline Unknown & $102(7 \cdot 0)$ & $136(4 \cdot 1)$ \\
\hline \multicolumn{3}{|l|}{ ASA fitness grade } \\
\hline 1 & $516(35 \cdot 6)$ & $1127(34 \cdot 2)$ \\
\hline II & $704(48.5)$ & $1746(53 \cdot 0)$ \\
\hline III & $204(14 \cdot 1)$ & $387(11.8)$ \\
\hline$\geq I V$ & $12(0 \cdot 8)$ & $9(0.3)$ \\
\hline Unknown & $15(1.0)$ & $24(0 \cdot 7)$ \\
\hline \multicolumn{3}{|l|}{ Indication } \\
\hline Biliary colic & $295(20 \cdot 3)$ & $955(29 \cdot 0)$ \\
\hline Acute cholecystitis & $795(54 \cdot 8)$ & $1369(41 \cdot 6)$ \\
\hline Pancreatitis & $268(18.5)$ & $545(16 \cdot 6)$ \\
\hline CBD stone & $83(5 \cdot 7)$ & $386(11 \cdot 7)$ \\
\hline Polyp & $2(0 \cdot 1)$ & $16(0.5)$ \\
\hline Dyskinesia & $1(0.1)$ & $9(0.3)$ \\
\hline Acalculous & $6(0.4)$ & $11(0 \cdot 3)$ \\
\hline Other/missing & $1(0 \cdot 1)$ & $2(0 \cdot 1)$ \\
\hline Ultrasonography performed & $1348(92.9)$ & $3163(96 \cdot 1)$ \\
\hline \multicolumn{3}{|l|}{ Ultrasound findings } \\
\hline Thick-walled & $729(50 \cdot 2)$ & $1412(42 \cdot 9)$ \\
\hline CBD dilated & $289(19.9)$ & $793(24 \cdot 1)$ \\
\hline CT performed & $290(20 \cdot 0)$ & $680(20 \cdot 6)$ \\
\hline MRCP performed & $417(28 \cdot 7)$ & $1319(40 \cdot 1)$ \\
\hline ERCP performed & $139(9.6)$ & $670(20 \cdot 3)$ \\
\hline
\end{tabular}

Values in parentheses are percentages. CBD, common bile duct; MRCP, magnetic retrograde cholangiopancreatography; ERCP, endoscopic retrograde cholangiopancreatography.

\section{Statistical analysis}

Results are reported in accordance with the STROBE statement for observational studies ${ }^{27}$. Crude rates of emergency cholecystectomy for all patients at each hospital were calculated.

Descriptive statistics were obtained for all variables. The $\chi^{2}$ test was used to identify differences between categorical variables. To enable exploration of between-hospital variation in the performance of emergency cholecystectomy, the data were analysed by means of multilevel, multivariable
Table 2 Hospital factors in relation to performance of emergency and delayed cholecystectomy

\begin{tabular}{|c|c|c|}
\hline & $\begin{array}{l}\text { Emergency } \\
\text { cholecystectomy } \\
(n=1451)\end{array}$ & $\begin{array}{c}\text { Delayed } \\
\text { cholecystectomy } \\
(n=3293)\end{array}$ \\
\hline University hospital & $764(52 \cdot 7)$ & $1378(41.8)$ \\
\hline Specialist HPB centre & $510(35 \cdot 1)$ & $705(21.4)$ \\
\hline Acute hospital & $1438(99 \cdot 1)$ & 3071 (93.3) \\
\hline $\begin{array}{l}\text { No. of consultants performing } \\
\text { cholecystectomies }^{*}\end{array}$ & $9(4-8)$ & $8(3-4)$ \\
\hline \multicolumn{3}{|l|}{ Country } \\
\hline England & $1038(71.5)$ & $2696(81.9)$ \\
\hline Northern Ireland & $53(3.7)$ & $98(3.0)$ \\
\hline Republic of Ireland & $59(4 \cdot 1)$ & $157(4 \cdot 8)$ \\
\hline Scotland & $251(17 \cdot 3)$ & $245(7.4)$ \\
\hline Wales & $50(3.4)$ & $97(2.9)$ \\
\hline \multicolumn{3}{|l|}{ No. of hospital beds } \\
\hline$\leq 100$ & $1(0 \cdot 1)$ & $21(0 \cdot 6)$ \\
\hline $101-500$ & $442(30.5)$ & $1377(41.8)$ \\
\hline $501-1000$ & $697(48.0)$ & $1579(48.0)$ \\
\hline$>1000$ & $311(21.4)$ & $316(9.6)$ \\
\hline ERCP service & $1382(95 \cdot 2)$ & $3094(94.0)$ \\
\hline \multicolumn{3}{|l|}{ Ease of performing $I O C$} \\
\hline Not possible & $22(1.5)$ & $121(3 \cdot 7)$ \\
\hline With difficulty & $212(14 \cdot 6)$ & $722(21.9)$ \\
\hline With ease & 1217 (83.9) & $2450(74.4)$ \\
\hline \multicolumn{3}{|l|}{$\begin{array}{l}\text { Emergency gallbladder } \\
\text { operating lists }\end{array}$} \\
\hline No & $993(68.4)$ & $2225(67 \cdot 6)$ \\
\hline Ad hoc & $152(10.5)$ & $403(12 \cdot 2)$ \\
\hline Once per week & $162(11 \cdot 2)$ & $212(6 \cdot 4)$ \\
\hline More than once per week & $138(9 \cdot 5)$ & $292(8.9)$ \\
\hline $\begin{array}{l}\text { Elective surgery only at } \\
\text { hospital }\end{array}$ & $6(0.4)$ & $161(4 \cdot 9)$ \\
\hline \multicolumn{3}{|l|}{ Consultant specialty } \\
\hline Oesophagogastric & $560(38.6)$ & $1220(37.0)$ \\
\hline HPB & $314(21 \cdot 6)$ & $634(19 \cdot 3)$ \\
\hline Colorectal & $352(24 \cdot 3)$ & $831(25 \cdot 2)$ \\
\hline Breast & $42(2 \cdot 9)$ & $137(4 \cdot 2)$ \\
\hline Vascular & $57(3.9)$ & $141(4 \cdot 3)$ \\
\hline Other & $117(8 \cdot 1)$ & $327(9.9)$ \\
\hline \multicolumn{3}{|l|}{ Hospital volume } \\
\hline High & $549(37 \cdot 8)$ & $969(29.4)$ \\
\hline Medium & 497 (34.3) & $1141(34.6)$ \\
\hline Low & $405(27.9)$ & $1183(35.9)$ \\
\hline
\end{tabular}

Values in parentheses are percentages unless indicated otherwise; *values are median (i.q.r.). HPB, hepatopancreatobiliary; ERCP, endoscopic retrograde cholangiopancreatography; IOC, intraoperative cholangiography.

logistic regression modelling using a two-level hierarchical structure with patients at level 1 , nested within hospitals at level 2. Initially a null two-level model was fitted, containing no explanatory variables, examining hospital-only effects. This model estimated the log-odds ratio (OR) of a patient receiving an emergency cholecystectomy at an 'average' hospital. The residual value was a measure of the variation at each hospital for a patient receiving an emergency cholecystectomy, calculated by subtracting the 


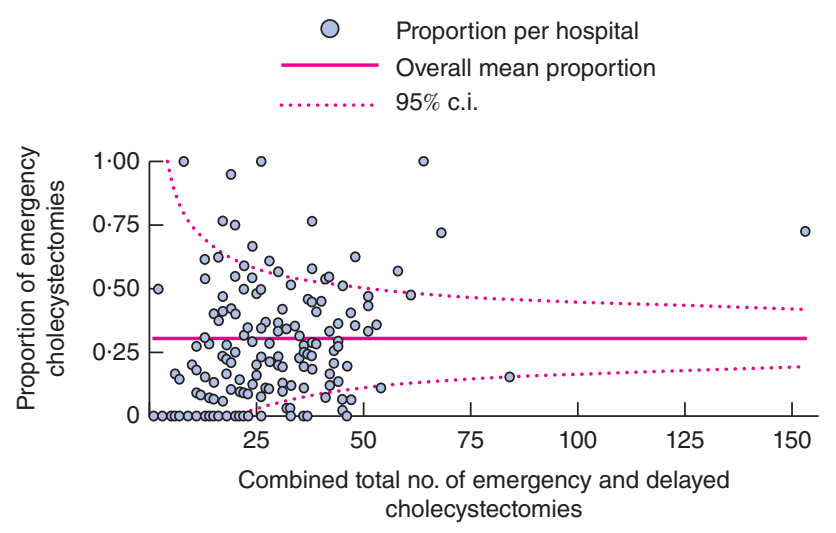

a All patients

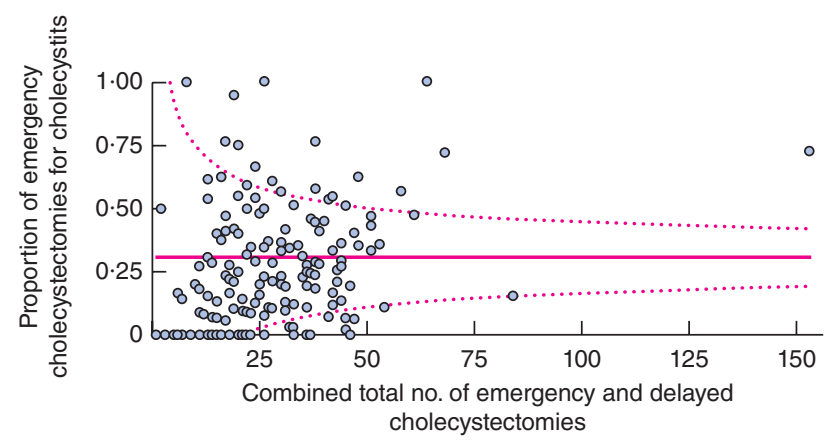

C Patients with cholecystitis
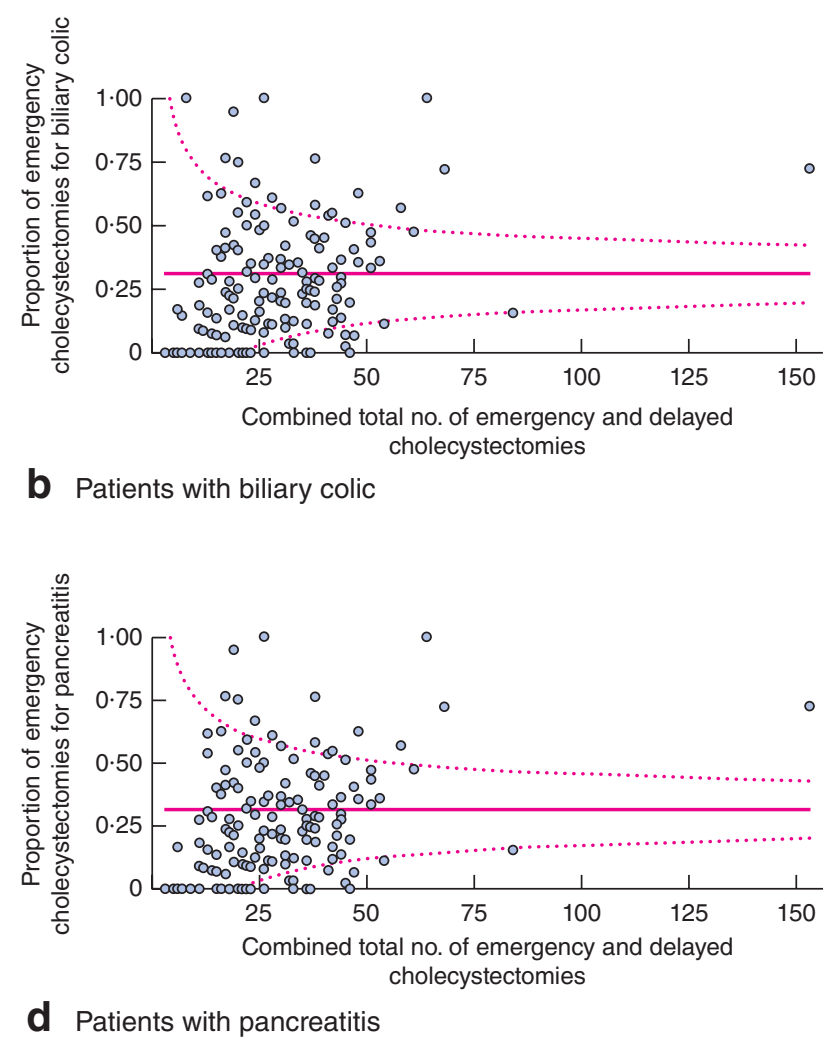

Fig. 1 Centre-specific performance of emergency cholecystectomy for a all patients, and those with $\mathbf{b}$ biliary colic, $\mathbf{c}$ acute cholecystitis and $\mathbf{d}$ pancreatitis

estimated log-OR for an average hospital from each hospital's estimated log-OR. The residual values were plotted in ascending order of magnitude with their respective 95 per cent confidence intervals (c.i.).

Explanatory variables were evaluated to determine whether any could explain the variation in performance of emergency cholecystectomy between hospitals, using a random intercept model. Univariable multilevel models were applied separately to each individual variable, investigating the significance of the variable as a whole and also the significance at each sublevel. No explanatory variables were excluded from the multivariable multilevel model building in order to allow for the presence of any confounders. Variable inclusion followed the forward and back Collett method for selection ${ }^{28}$. All two-way interactions were assessed to ensure that there were no significant interactions in the final model. Model testing was performed using likelihood ratio tests, Wald tests, residuals and deviance plots. When the multivariable random intercept model was finalized, the variance partition coefficient was calculated. This gives a measure of the amount of residual variation in the propensity of a patient to receive an emergency cholecystectomy that can be attributable to unobserved characteristics.

To investigate further the variations between hospitals, the random intercept model was extended to a random coefficient model, including each explanatory variable in turn, allowing the variable to vary across hospitals. Results are expressed as adjusted ORs with 95 per cent confidence intervals.

Finally, to provide a real-world interpretation of the data, the multilevel random intercept model was constructed using patient data whose true cholecystectomy surgery type (emergency or delayed) was known. Predicted probabilities were obtained using the model, based on patient characteristics for five common scenarios. The predicted probabilities obtained were grouped by patients known to have received either an emergency or delayed cholecystectomy. The mean predicted probabilities and corresponding 95 per cent confidence intervals were plotted.

All statistical methods were performed using Stata ${ }^{\circledR}$ version 12 (StataCorp, College Station, Texas, USA). The 


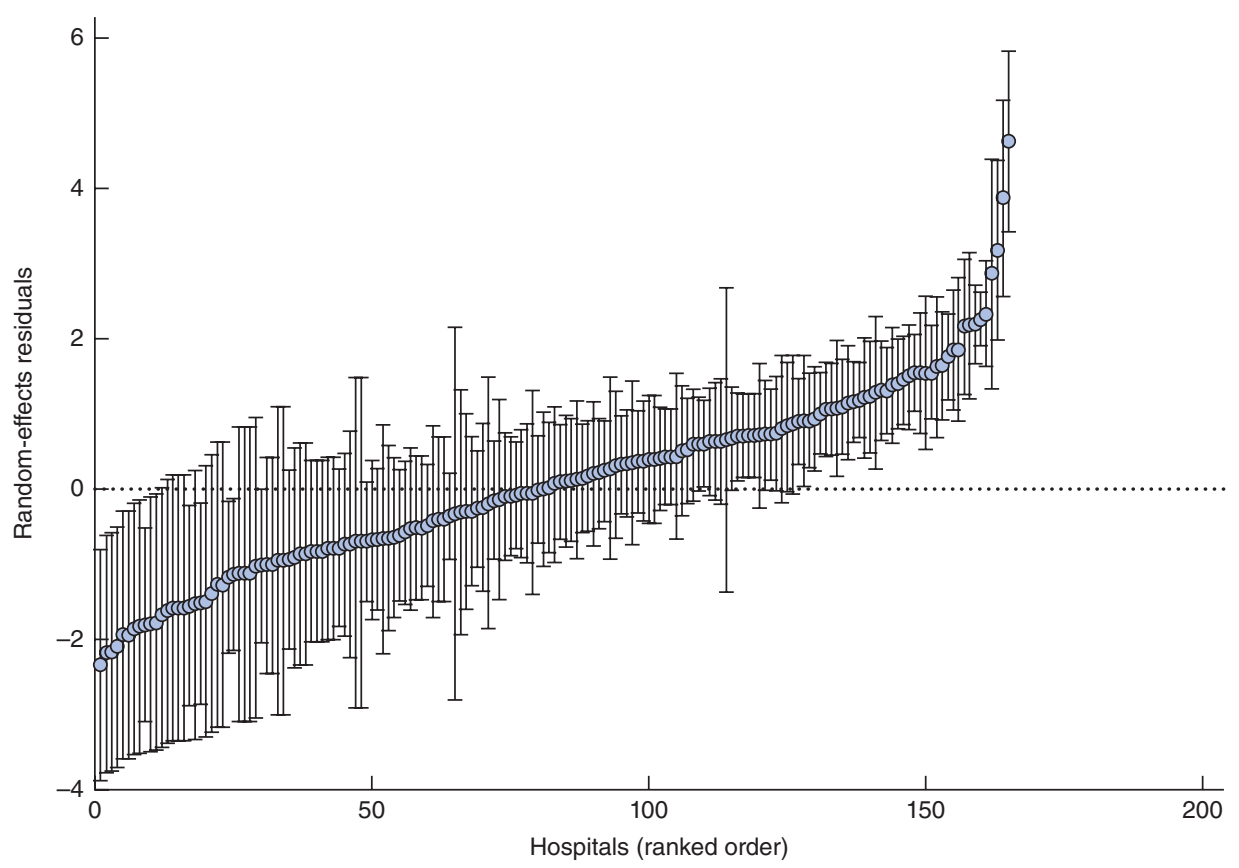

Fig. 2 Plot examining hospital effects (residuals) and corresponding 95 per cent confidence intervals

multilevel, multivariable logistic regression modelling was carried out in MLwiN version 2.14 (http://www.cmm. bristol.ac.uk/MLwiN).

\section{Results}

Data were collected on 8914 patients undergoing cholecystectomy from 166 hospitals, using a prospectively developed database and agreed starting date, between 1 March 2014 and 1 May 2014. Case ascertainment and accuracy of collected data were 95.2 and 99.2 per cent respectively. Data from 23.3 per cent of all patients (2077 of 8914) were checked against the original medical records by independent data validators. This equated to 11.1 per cent of all data points (64409 of 579410). Within the entire data set, 0.8 per cent of data were missing. Of the 8914 patients, 4744 in 165 hospitals met the inclusion criteria. Data were complete for 4698 patients and 1451 (30.9 per cent) underwent emergency cholecystectomy.

Overall demographics according to whether surgery was carried out as an emergency or delayed are shown in Table 1. Patients undergoing emergency cholecystectomy were younger than those having delayed surgery: median (i.q.r.) age $50(35-65)$ versus $54(39-67 \cdot 0)$ years $(P<0 \cdot 001)$. In addition, patients undergoing emergency cholecystectomy had higher ASA grades $(P=0.002)$, greater BMI $(P=0.034)$ and were more likely to have presented with acute cholecystitis or pancreatitis $(P<0 \cdot 001)$.
Considering hospital factors, 2142 ( $45 \cdot 2$ per cent) of all cholecystectomies were performed in university-affiliated hospitals and 1215 (25.6 per cent) in specialist HPB centres (Table 2). Emergency cholecystectomies were more likely to be performed in university hospitals $(P<0 \cdot 001)$, specialist HPB centres $(P<0 \cdot 001)$, hospitals with more beds $(P<0.001)$, and hospitals that performed a higher volume of procedures during the study period $(P<0 \cdot 001)$. Surgeons with a background in oesophagogastric or HPB surgery performed a greater proportion of the emergency operations than delayed operations $(60.2$ versus 56.3 per cent; $P=0.011$ ).

\section{Emergency cholecystectomy rates across hospitals}

There was marked variation in the rate of emergency cholecystectomy across hospitals (mean(s.d.) 26.4(23.3) per cent (range $0-100)$ per cent). This remained evident even when the analysis was limited to patients with acute cholecystitis, pancreatitis or biliary colic (Fig. 1).

When the data were analysed by means of multilevel logistic regression modelling using a two-level hierarchical structure with 4698 patients at level 1, nested within 165 hospitals at level 2, to enable exploration of between-hospital variation in the performance of emergency cholecystectomy, the null random intercept model fitted with hospital-only effects generated estimates of a patient receiving an emergency cholecystectomy (Fig. 2). 
Table 3 Multilevel random intercept logistic regression of association between patient and hospital characteristics and receipt of an emergency cholecystectomy

\begin{tabular}{|c|c|c|}
\hline & $\begin{array}{l}\text { Odds ratio } \\
\text { for emergency } \\
\text { versus delayed } \\
\text { cholecystectomy }\end{array}$ & $P$ \\
\hline \multicolumn{3}{|l|}{ Patient factors } \\
\hline \multicolumn{3}{|l|}{ Age (years) } \\
\hline$<40$ & 1.00 (reference) & \\
\hline $40-60$ & $0.68(0.56,0.84)$ & $<0.001$ \\
\hline $61-80$ & $0.54(0.42,0.68)$ & $<0.001$ \\
\hline$>80$ & $0.48(0.31,0.74)$ & 0.001 \\
\hline \multicolumn{3}{|l|}{ Sex } \\
\hline $\mathrm{F}$ & 1.00 (reference) & \\
\hline M & $0.84(0.70,1.01)$ & 0.058 \\
\hline \multicolumn{3}{|l|}{$\mathrm{BMI}\left(\mathrm{kg} / \mathrm{m}^{2}\right)$} \\
\hline $18 \cdot 0-24 \cdot 9$ & 1.00 (reference) & \\
\hline$<17.9$ & $2.12(0.78,6.36)$ & 0.179 \\
\hline $25 \cdot 0-29 \cdot 9$ & $1.23(0.98,1.54)$ & 0.069 \\
\hline $30 \cdot 0-34.9$ & $1.15(0.91,1.47)$ & 0.247 \\
\hline$\geq 35.0$ & $1.12(0.85,1.46)$ & 0.411 \\
\hline \multicolumn{3}{|l|}{ ASA fitness grade } \\
\hline 1 & 1.00 (reference) & \\
\hline II & $0.96(0.79,1.16)$ & 0.670 \\
\hline III & $1.43(1.07,1.91)$ & 0.016 \\
\hline$\geq \mathrm{IV}$ & $4.70(1.45,15 \cdot 25)$ & 0.010 \\
\hline \multicolumn{3}{|l|}{ Indication } \\
\hline Biliary colic & 1.00 (reference) & \\
\hline Acute cholecystitis & $2 \cdot 23(1.77,2.80)$ & $<0.001$ \\
\hline Pancreatitis & $2.39(1.85,3.10)$ & $<0.001$ \\
\hline CBD stone & $1.12(0.76,1.65)$ & 0.570 \\
\hline \multicolumn{3}{|c|}{ Gallbladder wall on ultrasonography } \\
\hline Normal & 1.00 (reference) & \\
\hline Thickened & $1.20(0.99,1.44)$ & 0.057 \\
\hline \multicolumn{3}{|c|}{ CBD diameter on ultrasonography } \\
\hline Normal & 1.00 (reference) & \\
\hline Dilated & $1.30(1.04,1.62)$ & 0.019 \\
\hline \multicolumn{3}{|l|}{ MRCP } \\
\hline No & 1.00 (reference) & \\
\hline Yes & $0.64(0.53,0.77)$ & $<0.001$ \\
\hline \multicolumn{3}{|l|}{ ERCP } \\
\hline No & 1.00 (reference) & \\
\hline Yes & $0.49(0.37,0.65)$ & $<0.001$ \\
\hline \multicolumn{3}{|l|}{ Hospital factors } \\
\hline \multicolumn{3}{|l|}{ Specialist HPB centre } \\
\hline No & 1.00 (reference) & \\
\hline Yes & $2.67(1.51,4.71)$ & 0.001 \\
\hline \multicolumn{3}{|l|}{ Acute hospital } \\
\hline No & 1.00 (reference) & \\
\hline Yes & $12 \cdot 61(4.04,39 \cdot 35)$ & $<0.001$ \\
\hline
\end{tabular}

Values in parentheses are 95 per cent confidence intervals. CBD, common bile duct; MRCP, magnetic retrograde cholangiopancreatography; ERCP, endoscopic retrograde cholangiopancreatography; HPB, hepatopancreatobiliary.

For 104 hospitals (63.0 per cent), the 95 per cent confidence interval crossed the zero line, indicating that the number of emergency cholecystectomies was not significantly different from average. In 46 hospitals (27.9 per cent), the 95 per cent confidence interval lay entirely above

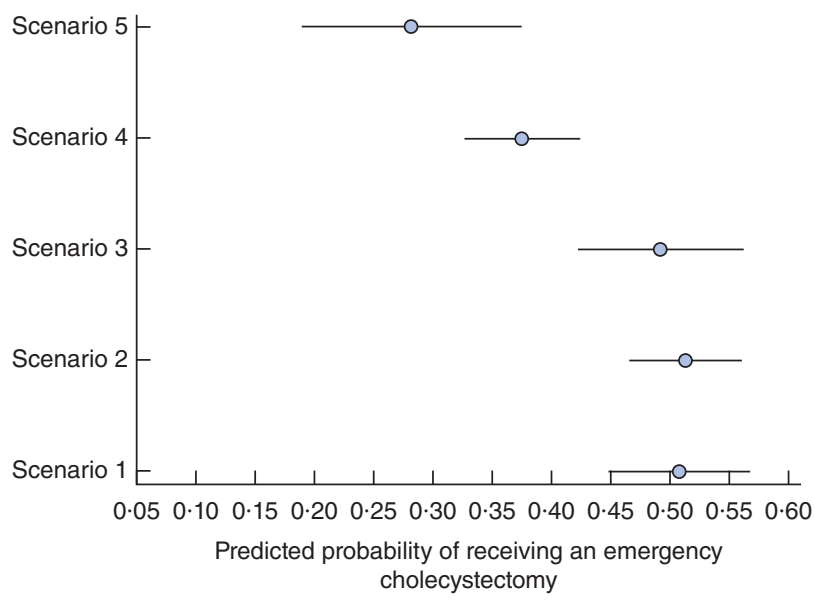

Fig. 3 Mean probability of receiving an emergency cholecystectomy, with corresponding 95 per cent confidence intervals, for patient scenarios calculated by the multilevel model

the zero line, suggesting that they performed a higher than average number of emergency cholecystectomies. In contrast, 15 hospitals ( $9 \cdot 1$ per cent) performed significantly lower numbers of emergency cholecystectomies than average. There was strong evidence of interhospital variation for having an emergency cholecystectomy (likelihood ratio statistic $848 \cdot 4, P<0 \cdot 001)$.

\section{Effect of co-variables on variation in emergency cholecystectomy rates}

The random intercept model was extended to include explanatory variables (Appendix S1, supporting information), producing a multilevel logistic random intercept model (Table 3). Increasing age, biliary colic, the need for further radiological imaging and interventions, endoscopic interventions and admission to a non-specialist HPB centre all significantly reduced the likelihood of an emergency cholecystectomy being performed. Hospital volume was not a significant factor. Following the inclusion of explanatory variables in the model, the estimated between-hospital variation decreased from $2 \cdot 0$ to $1 \cdot 8$, indicating that the distribution of the explanatory variables differed across hospitals. To determine how much variation between hospitals was explained by inclusion of the variables (age, sex, ASA grade, BMI, indication, ultrasound findings, MRCP, ERCP, specialist HPB centre and acute hospital status) within this model, the variance partition coefficient was calculated. Within the model, 65 per cent of the variation was attributable to hospital characteristics.

To show how much variation was seen for a given patient across the 165 hospitals, the random intercept model was used to calculate the probability of receiving an emergency 
cholecystectomy for a woman with: ASA grade I or II, BMI at least $25.0 \mathrm{~kg} / \mathrm{m}^{2}$, acute cholecystitis, ultrasound imaging showing a thick-walled gallbladder and normal CBD, and age 40 years or more (scenario 1) or less than 40 years (scenario 2). In addition, the probability of receiving an emergency cholecystectomy was predicted for three further examples: any patient aged 60 years or less with pancreatitis (scenario 3) or biliary colic requiring no further investigations (scenario 4) or requiring MRCP (scenario 5). Fig. 3 shows the predicted probability for a patient receiving an emergency cholecystectomy together with corresponding 95 per cent confidence intervals for the five scenarios. For scenario 1, the mean predicted probability of receiving an emergency cholecystectomy was 0.52 (95 per cent c.i. 0.45 to 0.57 ). The predicted probabilities, however, ranged from 0.02 to 0.95 across the 165 hospitals, demonstrating significant between-hospital variation for this common clinical presentation. For the scenarios described, the need for further imaging and certain diagnoses seemed to reduce the probability of receiving an emergency cholecystectomy.

\section{Discussion}

This population-based study, using prospectively collected data, with high rates of complete data, evaluated the practice of emergency cholecystectomy for acute gallbladder diseases. There was significant variation across UK and Irish hospitals, even when different gallbladder pathologies were considered. This was due to both patient (age, certain indications, need for further radiological imaging and interventions) and hospital (admission to a specialist HPB centre) factors. Patients with similar characteristics presenting to the 165 hospitals studied did not receive similar care.

Level 1 evidence supports emergency cholecystectomy for biliary colic, acute cholecystitis and gallstone pancreatitis, based on shortened total hospital stay, a similar conversion rate to open cholecystectomy and the elimination of recurrent gallstone symptoms, resulting in less time off work than with planned delayed cholecystectomy ${ }^{3-15,29}$. Although much of the supporting evidence comes from specialist institutions and enthusiasts, population-level data suggest that emergency cholecystectomy may be associated with poorer patient outcomes ${ }^{2,30}$. The findings of the present population-based cohort study are consistent with those of other cohort studies demonstrating different practices and variations in emergency cholecystectomy across hospitals ${ }^{16-20}$. These earlier studies suggested that variations were related to age, patient co-morbidities, surgeons' competing elective clinical obligations, comfort with emergency laparoscopy, the availability of hospital resources and insurance status ${ }^{31-33}$.

The present prospective study collected and independently validated data obtained from trainee-led networks in the UK and Ireland. This methodology is powerful when studying surgical variations ${ }^{34,35}$. Variations between hospitals in the performance of emergency cholecystectomy were analysed using multilevel, multivariable logistic regression modelling. This identified both patient and hospital variables accounting for the between-hospital variation seen. The patient variables identified here (increasing age, co-morbidity and indication) seem predictable and have been noted previously ${ }^{21}$. The need for further radiological imaging and interventions, endoscopic interventions and hospital factors (such as admission to a specialist HPB centre) may in part be related to logistical barriers at certain institutions, and balanced against the pressures from other acute and elective procedures. Specialist HPB centres were associated with higher performance of emergency cholecystectomy. This may reflect a better understanding of the evidence comparing the outcomes of emergency and delayed cholecystectomy, or an enthusiasm to deliver an emergency cholecystectomy service.

There are limitations to this study. The data represent a 2-month snapshot of practice and may account for why hospital volume was not found to be important in this analysis, compared with other reports that have relied mainly on administrative data sets that may be incomplete or inaccurate $\mathrm{e}^{2,30}$. The extent of variation across hospitals in the present study was large, although the model accounted for only 65 per cent of the variation seen, suggesting the presence of other variables not characterized in this study. This may reflect factors that alter surgical decision-making which are difficult to quantify, such as complexity of other emergency admissions and pressures on emergency operating time. However, many surgeon characteristics, such as consultant subspecialty, would be expected to overlap with the hospital characteristics included here.

Initiatives targeting better delivery of all emergency surgical care, including a dedicated service for emergency surgery referrals, a surgeon-of-the-week practice model, operating room time during the day dedicated to emergency procedures, and 7-day working, have all been proposed as potential solutions ${ }^{36-39}$. For example, dedicated emergency surgery team and operating lists are believed to provide efficient management of patients with gallstone disease $e^{40-42}$. In the present study, however, performance of emergency cholecystectomy was not improved with emergency gallbladder operating lists, nor with increasing numbers of consultants who 
performed cholecystectomy. This again suggests that there are hospital-level barriers in the delivery of effective emergency cholecystectomy services.

Similar variations in the performance of emergency cholecystectomy have been noted in other healthcare systems ${ }^{16-20}$. Although the present study analysed data from patients treated in UK and Irish hospitals, patient and hospital characteristics are likely to be similar across other European and high-income countries. Here, 46 hospitals provided higher rates of emergency cholecystectomy than others. A qualitative service evaluation of these hospitals and selected centres that perform high rates of emergency cholecystectomy across high-income countries may provide a better understanding of the provision in these hospitals and provide a model for care.

\section{Collaborators}

Study management group: R. S. Vohra (Trent Oesophago-Gastric Unit, Nottingham University Hospitals NHS Trust, Nottingham, UK); S. Pasquali (Surgical Oncology Unit, Veneto Institute of Oncology IOV-IRCCS, Padova, Italy); A. J. Kirkham (Cancer Research UK Clinical Trials Unit, University of Birmingham, Birmingham, UK); P. Marriott, M. Johnstone, P. Spreadborough (West Midlands Research Collaborative, Academic Department of Surgery, University of Birmingham, Birmingham, UK); D. Alderson (Academic Department of Surgery, University of Birmingham, Birmingham, UK); E. A. Griffiths (Department of Upper Gastrointestinal Surgery, University Hospitals Birmingham NHS Foundation Trust, Birmingham, UK).

Other members of the CholeS Study Group and West Midlands Research Collaborative are as follows. England: S. Fenwick, M. Elmasry, Q. Nunes, D. Kennedy (Aintree University Hospital NHS Foundation Trust); R. Basit Khan, M. A. S. Khan (Airedale General Hospital); C. J. Magee, S. M. Jones, D. Mason, C. P. Parappally (Wirral University Teaching Hospital); P. Mathur, M. Saunders, S. Jamel, S. Ul Haque, S. Zafar (Barnet and Chase Farm Hospital); M. H. Shiwani, N. Samuel, F. Dar, A. Jackson (Barnsley District General Hospital); B. Lovett, S. Dindyal, H. Winter, T. Fletcher, S. Rahman (Basildon Univesity Hospital); K. Wheatley, T. Nieto, S. Ayaani (Sandwell and West Birmingham Hospitals NHS Trust); H. Youssef, R. S. Nijjar, H. Watkin, D. Naumann, S. Emeshi, P. B. Sarmah, K. Lee, N. Joji (Heart of England Foundation NHS Trust); J. Heath, R. L. Teasdale, C. Weerasinghe (Blackpool Teaching Hospitals NHS Foundation Trust); P. J. Needham, H. Welbourn, L. Forster, D. Finch (Bradford Teaching Hospitals NHS Foundation Trust); J. M. Blazeby, W. Robb, A. G. K. McNair, A. Hrycaiczuk (University Hospitals Bristol NHS Trust); A. Charalabopoulos, S. Kadirkamanathan, C.-B. Tang, N. V. G. Jayanthi, N. Noor (Broomfield Hospital); B. Dobbins, A. J. Cockbain, A. Nilsen-Nunn, J. de Siqueira (Calderdale and Huddersfield NHS Trust); M. Pellen, J. B. Cowley, W.-M. Ho, V. Miu (Hull and East Yorkshire NHS Trust); T. J. White, K. A. Hodgkins, A. Kinghorn (Chesterfield Royal Hospital NHS Foundation Trust); M. G. Tutton, Y. A. Al-Abed, D. Menzies, A. Ahmad, J. Reed, S. Khan (Colchester Hospital University NHS Foundation Trust); D. Monk, L. J. Vitone, G. Murtaza, A. Joel (Countess of Chester NHS Foundation Trust); S. Brennan, D. Shier, C. Zhang, T. Yoganathan (Croydon Health Services NHS Trust); S. J. Robinson, I. J. D. McCallum, M. J. Jones, M. Elsayed, L. Tuck, J. Wayman, K. Carney (North Cumbria University Hospitals Trust); S. Aroori, K. B. Hosie, A. Kimble, D. M. Bunting, (Plymouth Hospitals NHS Trust); A. S. Fawole, M. Basheer, R. V. Dave,
J. Sarveswaran, E. Jones, C. Kendal (Mid Yorkshire NHS Trust); M. P. Tilston, M. Gough, T. Wallace, S. Singh, J. Downing, K. A. Mockford, E. Issa, N. Shah, N. Chauhan (Northern Lincolnshire and Goole NHS Foundation Trust); T. R. Wilson, A. Forouzanfar, J. R. L. Wild, E. Nofal, C. Bunnell, K. Madbak (Doncaster and Bassetlaw Hospitals NHS Foundation Trust); S. T V. Rao, L. Devoto, N. Siddiqi, Z. Khawaja (Dorset County Hospital NHS Foundation Trust); J. C. Hewes, L. Gould, A. Chambers, D. Urriza Rodriguez (North Bristol NHS Trust); G. Sen, S. Robinson, K. Carney, F. Bartlett (Freeman Hospital); D. M. Rae, T. E. J. Stevenson, K. Sarvananthan (Frimley Park Hospital NHS Trust); S. J. Dwerryhouse, S. M. Higgs, O. J. Old, T. J. Hardy, R. Shah, S. T. Hornby, K. Keogh, L. Frank (Gloucestershire Hospitals NHS Trust); M. Al-Akash, E. A. Upchurch (Great Western Hospitals NHS Foundation Trust); R. J. Frame, M. Hughes, C. Jelley (Harrogate and District NHS Foundation Trust); S. Weaver, S. Roy, T. O. Sillo, G. Galanopoulos (Wye Valley NHS Trust); T. Cuming, P. Cunha, S. Tayeh, S. Kaptanis (Homerton University Hospital NHS Trust); M. Heshaishi, A. Eisawi, M. Abayomi, W. S. Ngu, K. Fleming, D. Singh Bajwa (Tees Hospitals NHS Foundation Trust); V. Chitre, K. Aryal, P. Ferris (Paget University Hospitals NHS Foundation Trust); M. Silva, S. Lammy, S. Mohamed, A. Khawaja, A. Hussain, M. A. Ghazanfar, M. I. Bellini (Oxford University NHS Trust); H. Ebdewi, M. Elshaer, G. Gravante, B. Drake (Kettering General Hospital NHS Foundation Trust); A. Ogedegbe, D. Mukherjee, C. Arhi, L. Giwa Nusrat Iqbal (Barking, Havering and Redbridge University Hospitals NHS Trust); N. F. Watson, S. Kumar Aggarwal, P. Orchard, E. Villatoro (Kings Mill Hospital); P. D. Willson, K. Wa, J. Mok, T. Woodman, J. Deguara (Kingston Hospital NHS Foundation Trust); G. Garcea, B. I. Babu, A. R. Dennison, D. Malde, D. Lloyd, S. Satheesan, O. Al-Taan, A. Boddy (University Hospitals of Leicester NHS Trust); J. P. Slavin, R. P. Jones, L. Ballance, S. Gerakopoulos (Leighton Hospital, Mid Cheshire Hospitals NHS Foundation Trust); P. Jambulingam, S. Mansour, N. Sakai, V. Acharya (Luton and Dunstable University Hospital NHS Foundation Trust); M. M. Sadat, L. Karim, D. Larkin, K. Amin (Macclesfield District General Hospital); A. Khan, J. Law, S. Jamdar, S. R. Smith, K. Sampat, K. M O'Shea (Central Manchester NHS Foundation Trust); M. Manu, F. M. Asprou, N. S. Malik, J. Chang, M. Johnstone (Royal Wolverhampton Hospitals NHS Trust); M. Lewis, G. P. Roberts, B. Karavadra, E. Photi (Norfolk and Norwich University Hospitals NHS Foundation Trust); J. Hewes, L. Gould, A. Chambers, D. Rodriguez (North Bristol NHS Trust); D. A. O'Reilly, A. J. Rate, H. Sekhar, L. T. Henderson, B. Z. Starmer, P. O. Coe, S. Tolofari, J. Barrie (Pennine Acute NHS Trust); G. Bashir, J. Sloane, S. Madanipour, C. Halkias, A. E. J. Trevatt (North Middlesex Trust); D. W. Borowski, J. Hornsby, M. J. Courtney, S. Virupaksha (North Tees and Hartlepool NHS Foundation Trust); K. Seymour, S. Robinson, H. Hawkins, S. Bawa, P. V. Gallagher, A. Reid, P. Wood (Northumbria Healthcare NHS Foundation Trust); J. G. Finch, J. Parmar, E. Stirland (Northampton General Hospital NHS Trust); J. Gardner-Thorpe, A. Al-Muhktar, M. Peterson, A. Majeed (Sheffield Teaching Hospitals NHS Foundation Trust); F. M. Bajwa, J. Martin, A. Choy, A. Tsang (Peterborough City Hospital); N. Pore, D. R. Andrew, W. Al-Khyatt, C. Taylor, S. Bhandari, A. Chambers, D. Subramanium (United Lincolnshire Hospitals NHS Trust); S. K. C. Toh, N. C. Carter, S. J. Mercer, B. Knight, S. Tate, B. Pearce, D. Wainwright (Portsmouth Hospitals NHS Trust); V. Vijay, S. Alagaratnam, S. Sinha, S. Khan (The Princess Alexandra Hospital NHS Trust); S. S. El-Hasani, A. A. Hussain (King's College Hospital NHS Foundation Trust); V. Bhattacharya, N. Kansal, T. Fasih, C. Jackson (Gateshead Health NHS Foundation Trust); M. N. Siddiqui, I. A. Chishti, I. J. Fordham, Z. Siddiqui (Lewisham and Greenwich NHS Trust); H. Bausbacher, I. Geogloma, K. Gurung (Queen Elizabeth Hospital NHS Trust); G. Tsavellas, P. Basynat, A. Kiran Shrestha, S. Basu, A. Chhabra Mohan Harilingam, M. Rabie, M. Akhtar (East Kent Hospitals University NHS Foundation Trust); P. 
Kumar, S. F. Jafferbhoy, N. Hussain, S. Raza (Burton Hospitals NHS Foundation Trust); M. Haque, I. Alam, R. Aseem, S. Patel, M. Asad (Royal Albert Edward Infirmary, Wigan Wrightington and Leigh NHS Trust); $M$. I. Booth, W. R. Ball, C. P. J. Wood, A. C. Pinho-Gomes (Royal Berkshire NHS Foundation Trust); A. Kausar, M. Rami Obeidallah (East Lancashire Hospital Trust); J. Varghase, J. Lodhia, D. Bradley, C. Rengifo, D. Lindsay (Royal Bolton Hospital NHS Foundation Trust); S. Gopalswamy, I. Finlay, S. Wardle, N. Bullen (Royal Cornwall NHS Trust); S. Y. Iftikhar, A. Awan, J. Ahmed, P. Leeder (Royal Derby NHS Foundation Trust); G. Fusai, G. Bond-Smith, A. Psica, Y. Puri (Royal Free, London); D. Hou, F. Noble, K. Szentpali, J. Broadhurst (Hampshire Hospital NHS Foundation Trust); R. Date, M. R. Hossack, Y. Li Goh, P. Turner, V. Shetty (Lancashire Teaching Hospitals NHS Foundation Trust); M. Riera, C. A. W. Macano, A. Sukha (Royal Shrewsbury Hospital); S. R. Preston, J. R. Hoban, D. J. Puntis, S. V. Williams (Royal Surrey County Hospital NHS Foundation Trust); R. Krysztopik, J. Kynaston, J. Batt, M. Doe (Royal United Hospital Bath NHS Trust); A. Goscimski, G. H. Jones, S. R. Smith, C. Hall (Salford Royal NHS Foundation Trust); N. Carty, J. Ahmed, S. Panteleimonitis (Salisbury Hospital Foundation Trust); R. T. Gunasekera, A. R. G. Sheel, H. Lennon, C. Hindley (Southport and Ormskirk Hospital NHS Trust); M. Reddy, R. Kenny, N. Elkheir, E. R. McGlone (St George's Healthcare NHS Trust); R. Rajaganeshan, K. Hancorn, A. Hargreaves (St Helens and Knowsley Teaching Hospitals NHS Trust); R. Prasad, D. A. Longbotham, D. Vijayanand, I. Wijetunga (Leeds Teaching Hospitals); P. Ziprin, C. R. Nicolay, G. Yeldham, E. Read (Imperial College Healthcare NHS Trust); J. A. Gossage, R. C. Rolph, H. Ebied, M. Phull (St Thomas' Hospital, London); M. A. Khan, M. Popplewell, D. Kyriakidis, A. Hussain (Mid Staffordshire NHS Foundation Trust); N. Henley, J. R. Packer, L. Derbyshire, J. Porter (Stockport NHS Foundation Trust); S. Appleton, M. Farouk, M. Basra (Bucks Healthcare NHS Trust); N. A. Jennings, S. Ali, V. Kanakala (City Hospitals Sunderland NHS Foundation Trust); H. Ali, R. Lane, R. Dickson-Lowe, P. Zarsadias (Tunbridge Wells and Maidstone NHS Trust); D. Mirza, S. Puig, K. Al Amari, D. Vijayan, R. Sutcliffe, R. Marudanayagam (University Hospital Birmingham NHS Foundation Trust); Z. Hamady, A. R. Prasad, A. Patel (University Hospital Coventry and Warwickshire NHS Trust); D. Durkin, P. Kaur, L. Bowen (University Hospital of North Staffordshire NHS Trust); J. P. Byrne, K. L. Pearson, T. G. Delisle, J. Davies (University Hospital Southampton NHS Foundation Trust); M. A. Tomlinson, M. A. Johnpulle, C. Slawinski (University Hospitals of Morecambe Bay); A. Macdonald, J. Nicholson, K. Newton, J. Mbuvi (University Hospital South Manchester NHS Foundation Trust); A. Farooq, B. Sidhartha Mothe, Z. Zafrani, D. Brett (Warrington and Halton Hospitals NHS Trust); J. Francombe, P. Spreadborough, J. Barnes, M. Cheung (South Warwickshire NHS Foundation Trust); A. Z. Al-Bahrani, G. Preziosi, T. Urbonas (Watford General Hospital); J. Alberts, M. Mallik, K. Patel, A. Segaran, T. Doulias (West Suffolk NHS Trust); P. A. Sufi, C. Yao, S. Pollock (Whittington NHS Trust); A. Manzelli, S. Wajed, M. Kourkulos, R. Pezzuto (Wonford Hospital); M. Wadley, E. Hamilton, S. Jaunoo, R. Padwick (Worcestershire Acute Hospitals NHS Trust); M. Sayegh, R. C. Newton, M. Hebbar, S. F. Farag (Western Sussex Hospitals NHS Foundation Trust); J. Spearman, M. F. Hamdan, C. D’Costa, C. Blane (Yeovil District Hospital NHS Trust); M. Giles, M. B. Peter, N. A. Hirst, T. Hossain, A. Pannu, Y. El-Dhuwaib, T. E. M. Morrison, G. W. Taylor (York Teaching Hospital NHS Foundation Trust). Northern Ireland: R. L. E. Thompson, K. McCune, P. Loughlin, R. Lawther (Altnagelvin Area Hospital); C. K. Byrnes, D. J. Simpson, A. Mawhinney, C. Warren (Antrim Area Hospital); D. McKay, C. McIlmunn, S. Martin, M. MacArtney (Daisy Hill Hospital); T. Diamond, P. Davey, C. Jones, J. M. Clements, R. Digney, W. M. Chan, S. McCain, S. Gull, A. Janeczko, E. Dorrian, A. Harris, S. Dawson, D. Johnston, B. McAree (Belfast City Hospital, Mater Infirmorum Hospital Belfast and Royal Victoria Hospital); E. Ghareeb, G. Thomas,
M. Connelly, S. McKenzie, K. Cieplucha (South West Acute Hospital); G. Spence, W. Campbell, G. Hooks, N. Bradley (Ulster Hospital). Republic of Ireland: A. D. K. Hill, J. T. Cassidy, M. Boland (Beaumont Hospital, Dublin); P. Burke, D. M. Nally (University Hospital Limerick); A. D. K. Hill, E. Khogali, W. Shabo, E. Iskandar (Louth County Hospital and Our Lady of Lourdes Hospital); G. P. McEntee, M. A. O'Neill, C. Peirce, E. M. Lyons (Mater Hospital, Dublin); A. W. O'Sullivan, R. Thakkar, P. Carroll, I. Ivanovski (Mercy University Hospital); P. Balfe, M. Lee (St Luke's General Hospital, Kilkenny); D. C. Winter, M. E. Kelly, E. Hoti, D. Maguire, P. Karunakaran, J. G. Geoghegan, S. T. Martin, F. McDermott (St Vincent's University and Private Hospitals, Dublin); K. S. Cross, F. Cooke, S. Zeeshan, J. O. Murphy (Waterford Regional Hospital); K. Mealy, H. M. Mohan, Y. Nedujchelyn, M. Fahad Ullah (Wexford General Hospital). Scotland: I. Ahmed, F. Giovinazzo, J. Milburn (Aberdeen Royal Infirmary); S. Prince, E. Brooke, J. Buchan (Belford Hospital); A. M. Khalil, E. M. Vaughan, M. I. Ramage, R. C. Aldridge (Borders General Hospital); S. Gibson, G. A. Nicholson, D. G. Vass (Crosshouse Hospital, Ayrshire and Arran); A. J. Grant, D. J. Holroyd, M. A. Jones, C. M. L. R. Sutton (Dr Gray's Hospital); P. O'Dwyer, F. Nilsson (Gartnavel General Hospital); B. Weber, T. K. Williamson, K. Lalla, A. Bryant (Gilbert Bain Hospital); C. R. Carter, C. R. Forrest, D. I. Hunter (Glasgow Royal Infirmary); A. H. Nassar, M. N. Orizu, K. Knight, H. Qandeel (Monklands Hospital); S. Suttie, R. Belding, A. McClarey (Ninewells Hospital); A. T. Boyd, G. J. K. Guthrie, P. J. Lim, A. Luhmann (Perth Royal Infirmary); A. J. M. Watson, C. H. Richards, L. Nicol, M. Madurska (Raigmore Hospital); E. Harrison, K. M. Boyce, A. Roebuck, G. Ferguson (Royal Infirmary of Edinburgh); P. Pati, M. S. J. Wilson, F. Dalgaty, L. Fothergill (Stracathro Hospital); P. J. Driscoll, K. L. Mozolowski, V. Banwell, S. P. Bennett (Victoria Hospital, Kirkcaldy); P. N. Rogers, B. L. Skelly, C. L. Rutherford, A. K. Mirza (Western Infirmary, Glasgow). Wales: T. Lazim, H. C. C. Lim, D. Duke, T. Ahmed (Bronglais General Hospital); W. D. Beasley, M. D. Wilkinson, G. Maharaj, C. Malcolm (Glangwili General and Prince Philip Hospital); T. H. Brown, G. M. Shingler, N. Mowbray, R. Radwan (Morriston and Singleton Hospitals); P. Morcous, S. Wood, A. Kadhim (Princess of Wales Hospital); D. J. Stewart, A. L. Baker, N. Tanner, H. Shenoy (Wrexham Maelor Hospital). Data validators: S. Hafiz, J. A. De Marchi, D. Singh-Ranger, E. Hisham, P. Ainley, S. O'Neill, J. Terrace, S. Napetti, B. Hopwood, T. Rhys, J. Downing, O. Kanavati, M. Coats, D. Aleksandrov, C. Kallaway, S. Yahya, B. Weber, A. Templeton, M. Trotter, C. Lo, A. Dhillon, N. Heywood, Y. Aawsaj, A. Hamdan, O. Reece-Bolton, A. McGuigan, Y. Shahin, A. Ali, A. Luther, J. A. Nicholson, I. Rajendran, M. Boal, J. Ritchie.

\section{Acknowledgements}

The authors thank L. Billingham (Medical Research Council Midland Hub for Trials Methodology Research, University of Birmingham), D. Morton (University of Birmingham) and R. Lilford (University of Warwick) for statistical assistance and reviews of the manuscript.

Disclosure: The authors included in the trial management group of the CholeS study declare no conflict of interest.

\section{References}

1 Gurusamy KS, Davidson BR. Gallstones. BMF 2014; 348: g2669.

2 Sinha S, Hofman D, Stoker DL, Friend PJ, Poloniecki JD, Thompson MM et al. Epidemiological study of provision of cholecystectomy in England from 2000 to 2009: 
retrospective analysis of Hospital Episode Statistics. Surg Endosc 2013; 27: 162-175.

3 Gurusamy K, Samraj K, Gluud C, Wilson E, Davidson BR. Meta-analysis of randomized controlled trials on the safety and effectiveness of early versus delayed laparoscopic cholecystectomy for acute cholecystitis. Br 7 Surg 2010; 97: $141-150$.

4 Gurusamy KS, Koti R, Fusai G, Davidson BR. Early versus delayed laparoscopic cholecystectomy for uncomplicated biliary colic. Cochrane Database Syst Rev 2013; (6)CD007196.

5 Macafee DA, Humes DJ, Bouliotis G, Beckingham IJ, Whynes DK, Lobo DN. Prospective randomized trial using cost-utility analysis of early versus delayed laparoscopic cholecystectomy for acute gallbladder disease. Br 7 Surg 2009; 96: 1031-1040.

6 Society of American Gastrointestinal and Endoscopic Surgeons. Guidelines for the Clinical Application of Laparoscopic Biliary Tract Surgery. http://www.sages.org/publications/ guidelines/guidelines-for-the-clinical-application-oflaparoscopic-biliary-tract-surgery [accessed 25 November 2015].

7 Strasberg SM. Clinical practice. Acute calculous cholecystitis. N Engl 7 Med 2008; 358: 2804-2811.

8 Germanos S, Gourgiotis S, Kocher HM. Clinical update: early surgery for acute cholecystitis. Lancet 2007; 369 : 1774-1776.

9 UK guidelines for the management of acute pancreatitis. Gut 2005; 54(Suppl 3): iii1-iii9.

10 Siddiqui T, MacDonald A, Chong PS, Jenkins JT. Early versus delayed laparoscopic cholecystectomy for acute cholecystitis: a meta-analysis of randomized clinical trials. Am 7 Surg 2008; 195: 40-47.

11 Gutt CN, Encke J, Koninger J, Harnoss JC, Weigand K, Kipfmuller K et al. Acute cholecystitis: early versus delayed cholecystectomy, a multicenter randomized trial (ACDC study, NCT00447304). Ann Surg 2013; 258: 385-393.

12 Falor AE, de Virgilio C, Stabile BE, Kaji AH, Caton A, Kokubun BA et al. Early laparoscopic cholecystectomy for mild gallstone pancreatitis: time for a paradigm shift. Arch Surg 2012; 147: 1031-1035.

13 Kolla SB, Aggarwal S, Kumar A, Kumar R, Chumber S, Parshad R et al. Early versus delayed laparoscopic cholecystectomy for acute cholecystitis: a prospective randomized trial. Surg Endosc 2004; 18: 1323-1327.

14 Johansson M, Thune A, Blomqvist A, Nelvin L, Lundell L. Management of acute cholecystitis in the laparoscopic era: results of a prospective, randomized clinical trial. 7 Gastrointest Surg 2003; 7: 642-645.

15 de Mestral C, Rotstein OD, Laupacis A, Hoch JS, Zagorski B, Alali AS etal. Comparative operative outcomes of early and delayed cholecystectomy for acute cholecystitis: a population-based propensity score analysis. Ann Surg 2014; 259: 10-15.

16 Stephens MR, Beaton C, Steger AC. Early cholecystectomy after acute admission with cholecystitis: how much work? World 7 Surg 2010; 34: 2041-2044.
17 Lee SW, Yang SS, Chang CS, Yeh HJ. Impact of the Tokyo guidelines on the management of patients with acute calculous cholecystitis. $\mathcal{F}$ Gastroenterol Hepatol 2009; 24 : 1857-1861.

18 Casillas RA, Yegiyants S, Collins JC. Early laparoscopic cholecystectomy is the preferred management of acute cholecystitis. Arch Surg 2008; 143: 533-537.

19 Riall TS, Zhang D, Townsend CM Jr, Kuo YF, Goodwin JS. Failure to perform cholecystectomy for acute cholecystitis in elderly patients is associated with increased morbidity, mortality, and cost. 7 Am Coll Surg 2010; 210: 668-677, $677-669$

20 Greenstein AJ, Moskowitz A, Gelijns AC, Egorova NN. Payer status and treatment paradigm for acute cholecystitis. Arch Surg 2012; 147: 453-458.

21 de Mestral C, Laupacis A, Rotstein OD, Hoch JS, Haas B, Gomez D et al. Early cholecystectomy for acute cholecystitis: a population-based retrospective cohort study of variation in practice. CMAf Open 2013; 1: E62-E67.

22 Ghaferi AA, Birkmeyer JD, Dimick JB. Variation in hospital mortality associated with inpatient surgery. $N$ Engl 7 Med 2009; 361: 1368-1375.

23 McCulloch P, Nagendran M, Campbell WB, Price A, Jani A, Birkmeyer JD etal. Strategies to reduce variation in the use of surgery. Lancet 2013; 382: 1130-1139.

24 Houghton A. Variation in outcome of surgical procedures. $\mathrm{Br}$ 7 Surg 1994; 81: 653-660.

25 Bhangu A, Kolias AG, Pinkney T, Hall NJ, Fitzgerald JE. Surgical research collaboratives in the UK. Lancet 2013; 382: 1091-1092.

26 Vohra RS, Spreadborough P, Johnstone M, Marriott P, Bhangu A, Alderson D et al. Protocol for a multicentre, prospective, population-based cohort study of variation in practice of cholecystectomy and surgical outcomes (The CholeS study). BM7 Open 2015; 5: e006399.

27 von Elm E, Altman DG, Egger M, Pocock SJ, Gotzsche PC, Vandenbroucke JP. The Strengthening the Reporting of Observational Studies in Epidemiology (STROBE) statement: guidelines for reporting observational studies. Lancet 2007; 370: 1453-1457.

28 Collett D. Modelling Survival Data in Medical Research. Chapman \& Hall: London, 1994.

29 Wu XD, Tian X, Liu MM, Wu L, Zhao S, Zhao L. Meta-analysis comparing early versus delayed laparoscopic cholecystectomy for acute cholecystitis. Br F Surg 2015; 102: 1302-1313.

30 Harrison EM, O’Neill S, Meurs TS, Wong PL, Duxbury M, Paterson-Brown $\mathrm{S}$ et al. Hospital volume and patient outcomes after cholecystectomy in Scotland: retrospective, national population based study. BMF 2012; 344: e3330.

31 Campbell EJ, Montgomery DA, Mackay CJ. A national survey of current surgical treatment of acute gallstone disease. Surg Laparosc Endosc Percutan Tech 2008; 18: 242-247. 
32 Yamashita Y, Takada T, Hirata K. A survey of the timing and approach to the surgical management of patients with acute cholecystitis in Japanese hospitals. 7 Hepatobiliary Pancreat Surg 2006; 13: 409-415.

33 Cameron IC, Chadwick C, Phillips J, Johnson AG. Management of acute cholecystitis in UK hospitals: time for a change. Postgrad Med 7 2004; 80: 292-294.

34 Multicentre observational study of performance variation in provision and outcome of emergency appendicectomy. $\operatorname{Br} 7$ Surg 2013; 100: 1240-1252.

35 Impact of postoperative non-steroidal anti-inflammatory drugs on adverse events after gastrointestinal surgery. $\operatorname{Br} \mathcal{F}$ Surg 2014; 101: 1413-1423.

36 Hoyt DB. Looking forward. Bull Am Coll Surg 2011; 96: 5-6.

37 Royal College of Surgeons of England. Separating Emergency and Elective Surgical Care: Recommendations for Practice. http://www.rcseng.ac.uk/publications/docs/separating emergency_and_elective.html [accessed 1 July 2012].
38 Lau B, Difronzo LA. An acute care surgery model improves timeliness of care and reduces hospital stay for patients with acute cholecystitis. Am Surg 2011; 77: 1318-1321.

39 Simpson DJ, Wood AM, Paterson HM, Nixon SJ, Paterson-Brown S. Improved management of acute gallstone disease after regional surgical subspecialization. World 7 Surg 2008; 32: 2690-2694.

40 Agrawal S, Battula N, Barraclough L, Durkin D, Cheruvu $\mathrm{CV}$. Early laparoscopic cholecystectomy service provision is feasible and safe in the current UK National Health Service. Ann R Coll Surg Engl 2009; 91: 660-664.

41 Nagaraja V, Eslick GD, Cox MR. The acute surgical unit model versus the traditional 'on call' model: a systematic review and meta-analysis. World 7 Surg 2014; 38: 1381-1387.

42 Mercer SJ, Knight JS, Toh SK, Walters AM, Sadek SA, Somers SS. Implementation of a specialist-led service for the management of acute gallstone disease. Br F Surg 2004; 91: 504-508.

\section{Supporting information}

Additional supporting information may be found in the online version of this article:

Appendix S1 Variables included in multilevel random intercept logistic regression analysis of the association between patient and hospital characteristics and emergency cholecystectomy (Word document) 